\title{
An Investigation of Cooling and Heating Degree-Hours in Thailand
}

\author{
Kriengkrai Assawamartbunlue
}

\begin{abstract}
The simplest well-known method that can be used to preliminarily estimate energy consumption of buildings is the degree-days method that usually requires the knowledge of either annual or monthly cooling and heating degree-days. In this paper, annual and monthly degree-days of 4 major cities in Thailand are investigated based on hourly temperature data in term of "degree-hours." Long-term hourly temperature data for 15 years (1994-2008) are used to calculate degree-hours at various base temperatures. The Sandia method is used to make annual hourly temperature dataset that can represent a typical hourly temperature year instead of using long-term average hourly temperature. The results show that Bangkok has the highest annual and monthly cooling degree-hours followed by Songkla, Ubonratchathani, and Chiangmai. In all cities, the number of cooling degree-hours is much more than one of heating degree-hours which implies that energy consumption of buildings is used for space cooling much more than space heating. Regression models are also developed for determining annual cooling and heating degree-hours at any base temperature.
\end{abstract}

Index Terms-Cooling degree-hours, degree-days, heating degree-hours, Thailand, typical meteorological year

\section{INTRODUCTION}

One of significant meteorological variables that relate to building and residential energy consumption is heating (HDD) and cooling degree-days (CDD). Both of them are basic quantities for preliminarily estimating energy consumption of a building. Unfortunately the degree-days are not commonly used in the past few years because of advanced communication systems that allows one to be able to remotely access data storages or servers to directly retrieve data [1]. The data could be yearly, daily, hourly, or even subhourly whichever matches the users' requirements. Another reason is that effects of latent loads are not accounted into the degree-days.

Nevertheless HDD and CDD are still useful in preliminary energy audits to estimate savings of energy conservation measures (ECM) that depend on seasonal and outdoor temperature for which simple methods are more appropriate than complex and time-consuming methods. Thus there still are several researches in recent years to study and predict variations and trends of HDD and CDD at a particular location, such as China [2], London [3], and Turkish [4].

In addition to that, there were many researches that focused on developing mathematical models to predict

Manuscript received October 25, 2012; revised December 25, 2013.

Kriengkrai Assawamartbunlue is with Energy Technology Research Group, Mechanical Engineering Department, Kasetsart University, Thailand 10900 (e-mail: fengkka@ku.ac.th). degree-days. Thevenard [1] examined methods to determine degree-days to any base temperature and concluded that the method developed by Schoenau and Kehrig were the best. Kolokotroni [3] developed an artificial neural network models to predict hourly air temperature within the Greater London area that can be used to calculate HDD and CDD.

Adigun [5] used a statistical approach in terms of the probability density function (PDF) and cumulative distribution function (CDF) based on beta distribution to develop CDD model for Southern Nigeria. Oktay [6] developed a method to predict the daily outdoor temperature based on the daily maximum and minimum temperature from which the daily and monthly cooling degree-hours for buildings were then calculated.

Krese [7] proposed a method to include the influence of latent loads into the cooling degree-days concept. The latent loads were presented in the form of performance surface graph that was a plot of electric consumption as a function of CDD and latent enthalpy days. The proposed method was used to analyze electric energy consumption of a real building [8] and compared with convectional degree-days method.

As previously shown, degree-days still plays an important role in energy estimations and analysis that are worth to be investigated. The assessment is needed to indicate the energy demand of heating or cooling for buildings. Even though the degree-days is more common than the degree-hours due to the lack of hourly temperature data at a particular location, the degree-hours of 4 major cities of Thailand are presented at various base temperatures in this paper using measured hourly temperature data.

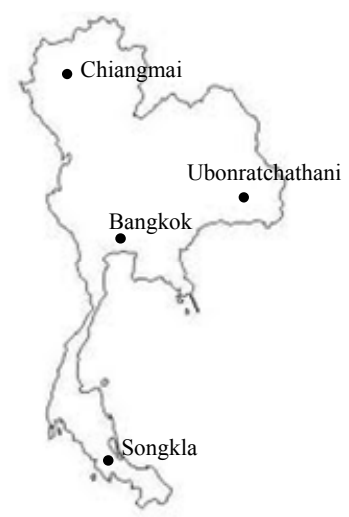

Fig. 1. Selected weather stations in Thailand.

\section{DATA AND METHODS}

\section{A. Data}

Based on physical geography, Thailand could be divided 
into four regions, i.e. central, north, north-east, and south region. One data station was carefully selected to represent each region based on availability and completeness of the data. They were Bangkok (Donmuang), Chiangmai, Songkla (Hat Yai), and Ubonratchathani, as shown in Fig 1. The hourly dry-bulb air temperature dataset of each station was provided by the Thai Meteorological Department for 15 consecutive years (1994-2008).

\section{B. Methodology}

An hourly dataset that represented typical temperature of each region was created from long-term data. Instead of using long term average for each particular hour to create hourly temperature of a whole year, individual months from different years of the period of record were selected using the Sandia method. The Sandia method was the method that was used to create TMY3 [9], a well-known meteorological dataset for computer simulations. The dry-bulb temperature was used as an index in the Sandia method.

Briefly, for each month, CDF of months for the daily index was calculated. Five candidate months with CDF closet to the long-term (15 years) were selected and then ranked with respect to closeness of the month to the long-term mean and median. The highest-ranked candidate month that meets the persistence criteria was used. The persistence criteria were set in such a way that the frequency and length of runs of consecutive days with values above and below fixed long-term percentiles. Finally, the 12 selected months were concatenated to make a complete year.

\section{Degree-Hours}

Heating and cooling degree-hours are defined as the sum of the differences between hourly average temperatures and the base temperature. The number of cooling degree-hours $(\mathrm{CDH})$ in a day is defined as

$$
C D H_{b}=\sum_{i=1}^{N}\left(T_{i}-T_{b}\right)^{+}
$$

where $N$ is the number of hours in the day, $T_{b}$ is the base temperature to which the degree-days are calculated, and $T_{i}$ is the average hourly temperature. The "+" superscript indicates that only positive values of the bracketed quantity are taken into account in the sum. Similarly, daily heating degree-hours (HDH) are defined as

$$
\mathrm{HDH}_{b}=\sum_{i=1}^{N}\left(T_{b}-T_{i}\right)^{+} .
$$

Monthly degree-hours are simply the sum of daily degree-hours over the number of days in the month. Likewise, yearly degree-hours are the sum of monthly degree-hours over the 12 months of the year.

\section{RESULTS}

Fig. 2 and Fig. 3 shows monthly cooling and heating degree-hours of the selected weather stations, respectively. It is obvious that most of energy in a building is consumed by cooling systems rather than heating systems due to hot and humid climate of Thailand. Most of the average hourly temperature is greater than the base temperature at $18.5 \mathrm{C}$ throughout the year. There are only a few hours when the outside temperature is lower than the base temperature in northern and north-eastern region, especially in winter. There are no heating season for Bangkok and Songkla. Thus, energy conservation measures that improve performances of cooling systems will have a great influence on energy consumption of buildings.

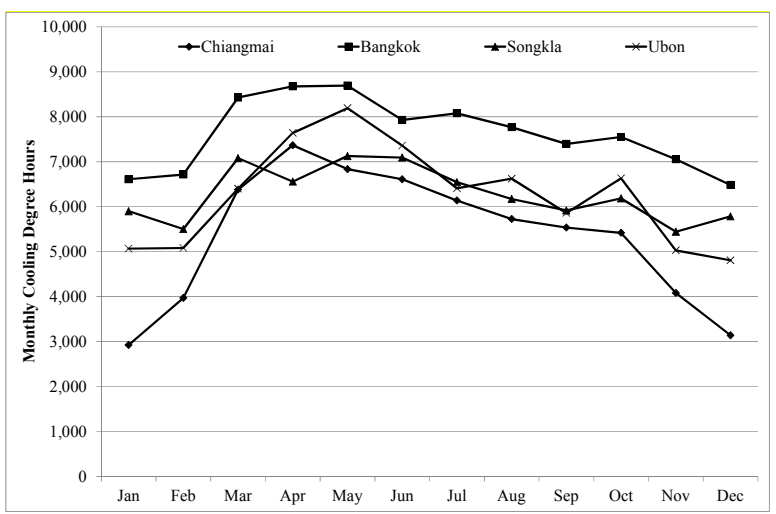

Fig. 2. Monthly cooling degree-hours at $\mathrm{T}_{\mathrm{b}}=18.5 \mathrm{C}$.

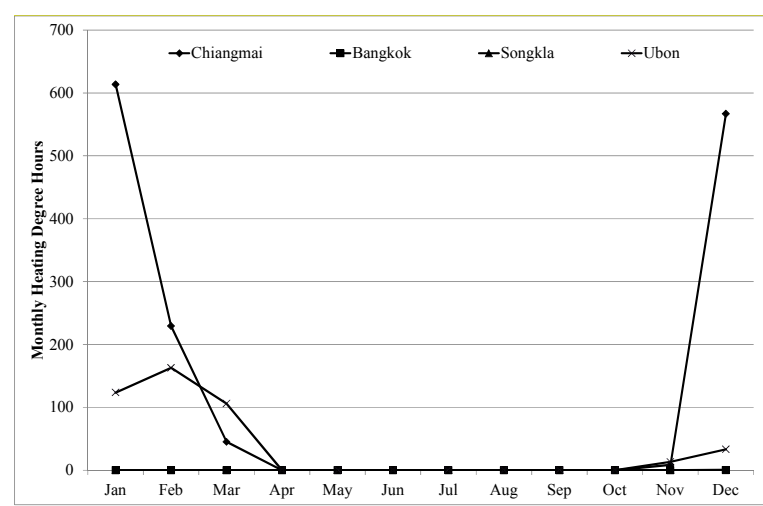

Fig. 3. Monthly heating degree-hours at $T_{b}=18.5 C$.

TABLE I: THE MONTHLy AVERAGE CDH

\begin{tabular}{lcccr}
\hline \hline Station & Mean & Min & Max & \multicolumn{1}{c}{ Std. } \\
\hline Chiangmai & 5,343 & 2,923 & 7,366 & 1,415 \\
Bangkok & 7,615 & 6,482 & 8,692 & 750 \\
Songkla & 6,275 & 5,443 & 7,127 & 579 \\
Ubonratchathani & 6,258 & 4,807 & 8,193 & 1,071 \\
\hline \hline
\end{tabular}

TABLE II: THE MONTHLY AVERAGE HDH

\begin{tabular}{lrrrr}
\hline \hline Station & Mean & Min & Max & \multicolumn{1}{c}{ Std. } \\
\hline Chiangmai & 122 & 0 & 614 & 219 \\
Bangkok & 0 & 0 & 1 & 0 \\
Songkla & 0 & 0 & 0 & 0 \\
Ubonratchathani & 37 & 0 & 163 & 56 \\
\hline \hline
\end{tabular}

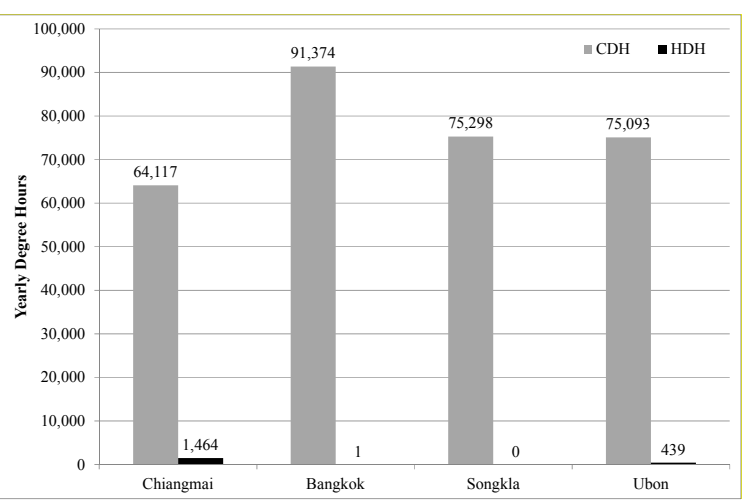

Fig. 4. Annual cooling and heating degree-hours at $\mathrm{T}_{\mathrm{b}}=18.5 \mathrm{C}$. 
Table I and Table II show basic statistical features of monthly $\mathrm{CDH}$ and $\mathrm{HDH}$ of selected stations. Bangkok has the highest $\mathrm{CDH}$ followed by Songkla, Ubonratchathani and Chiangmai. Bangkok and Songkla have relatively small variations compared to Chiangmai and Ubonratchathani. The monthly average HDH are very low in all stations and not significant in energy consumption of buildings.

Fig. 4 shows annual cooling and heating degree-hours. Bangkok, located at the central region, has the highest annual $\mathrm{CDH}$, while Chiangmai, located at the north region, has the lowest annual CDH. Annual CDH of Songkla is close to one of Ubonratchathani. Similar to monthly $\mathrm{CDH}$, annual $\mathrm{HDH}$ is relatively very small compared to annual $\mathrm{CDH}$. Therefore, hot air for space heating is not commonly required for most of buildings in Thailand throughout the year.

Fig. 5 - Fig. 8 show monthly $\mathrm{CDH}$ of each station for various base temperatures. The profile of each base temperature is quite similar to each other. Either April or May is the highest month, while either November or December is the lowest month. Fig. 9 - Fig. 12 show annual $\mathrm{CDH}$ and $\mathrm{HDH}$ for various base temperatures. The annual $\mathrm{CDH}$ and HDH for each particular stations at any base temperature can be approximated as shown in (3) to (10).

\section{A. Chiangmai}

$$
\begin{aligned}
& C D H_{T_{b}}=147.99 T_{b}^{2}-13588 T_{b}+264597 \\
H D H_{T_{b}}= & 13.268 T_{b}^{3}-648.12 T_{b}^{2}+10900 T_{b}-62376
\end{aligned}
$$

\section{B. Bangkok}

$$
\begin{array}{r}
C D H_{T_{b}}=22.082 T_{b}^{2}-9560.7 T_{b}+260619 \\
H D H_{T_{b}}=3.7133 T_{b}^{3}-200.72 T_{b}^{2}+3600.9 T_{b}-21434
\end{array}
$$

\section{Songkla}

$$
\begin{array}{r}
C D H_{T_{b}}=35.716 T_{b}^{2}-10085 T_{b}+249493 \\
H D H_{T_{b}}=10.18 T_{b}^{3}-575.06 T_{b}^{2}+10741 T_{b}-66318
\end{array}
$$

\section{Ubonratchathani}

$$
C D H_{T_{b}}=94.377 T_{b}^{2}-11949 T_{b}+263700
$$

$H D H_{T_{b}}=8.6708 T_{b}^{3}-425.87 T_{b}^{2}+7088.8 T_{b}-39841$

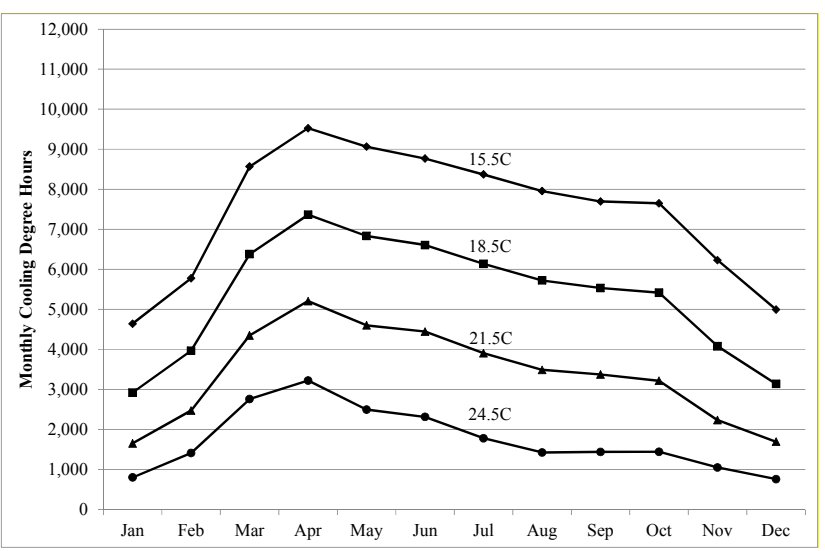

Fig. 5. Monthly $\mathrm{CDH}$ of Chiangmai at various base temperatures.

Fig. 9 - Fig. 12 also show comparisons between the proposed regression models and the Schoenau \& Kehrig model [1] on annual CDH. Schoenau \& Kehrig model implemented a statistical approach to estimate monthly CDD at any base temperature assuming that the daily mean temperatures are normally distributed around the monthly mean. It is obvious that the estimated CDH by Schoenau \& Kehrig model are overestimated by approximately $20-30 \%$.

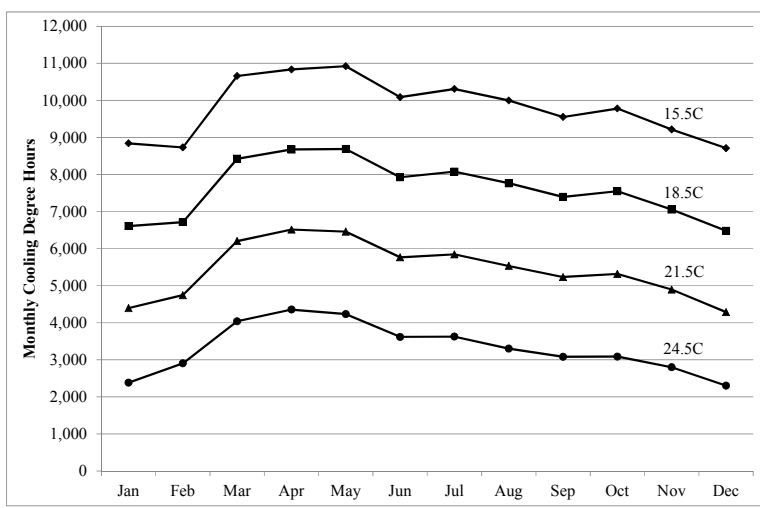

Fig. 6. Monthly $\mathrm{CDH}$ of Bangkok at various base temperatures.

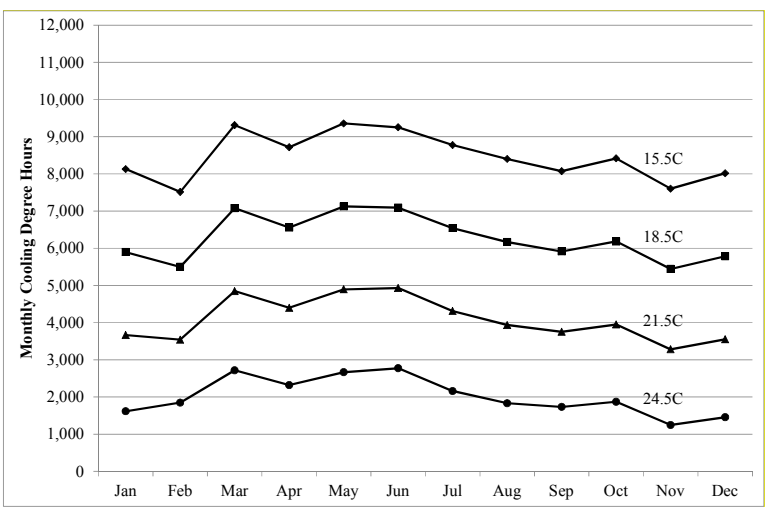

Fig. 7. Monthly $\mathrm{CDH}$ of Songkla at various base temperatures.

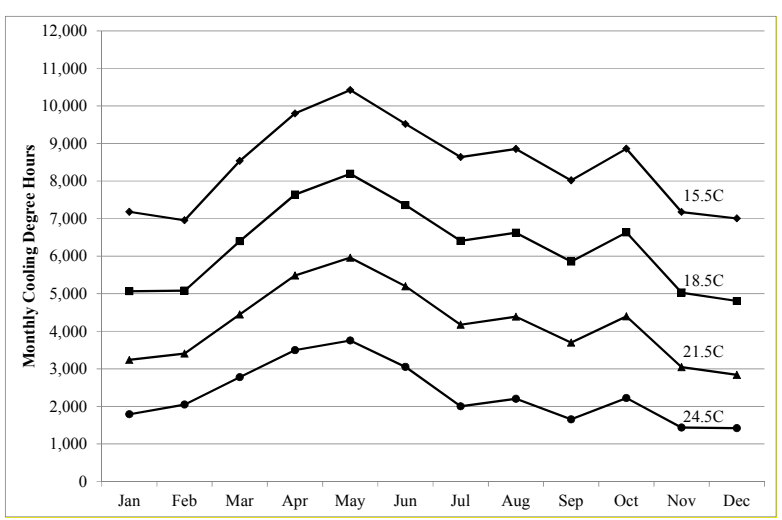

Fig. 8. Monthly CDH of Ubonratchathani at various base temperatures.

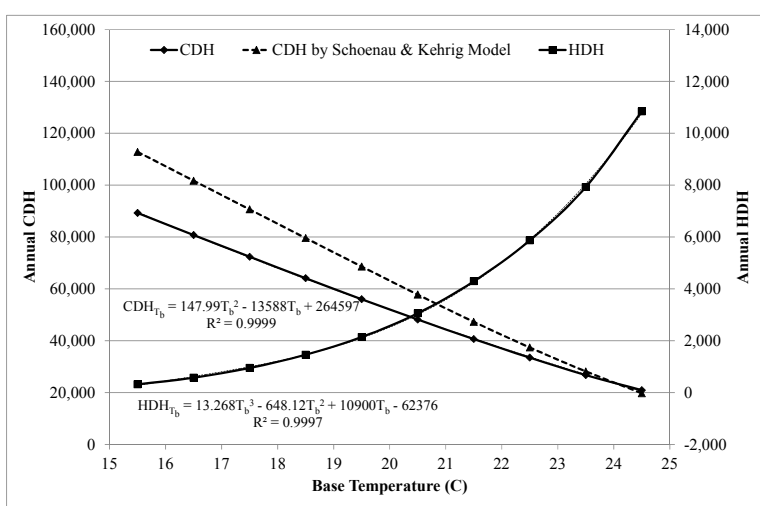

Fig. 9. Annual $\mathrm{CDH}$ and $\mathrm{HDH}$ of Chiangmai at various base temperatures. 


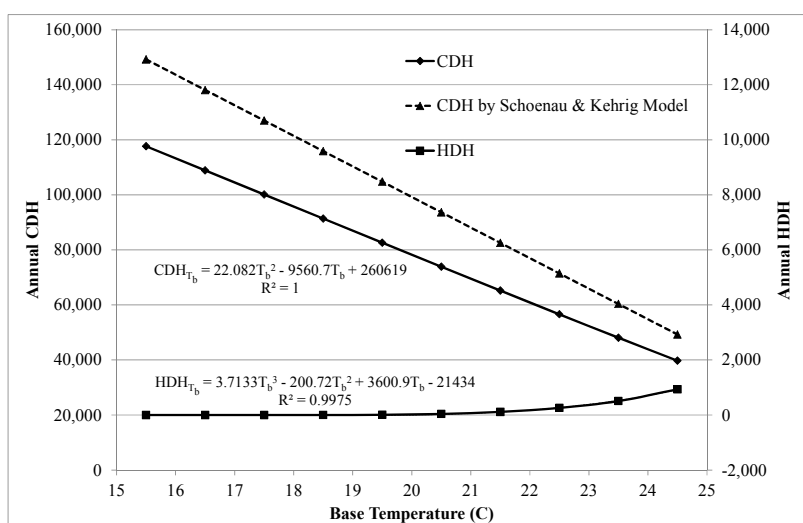

Fig. 10. Annual $\mathrm{CDH}$ and $\mathrm{HDH}$ of Bangkok at various base temperatures.

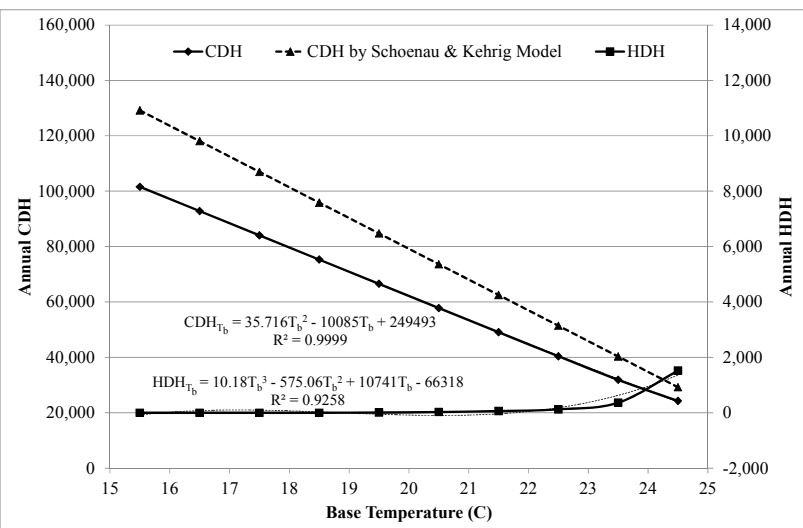

Fig. 11. Annual CDH and HDH of Songkla at various base temperatures.

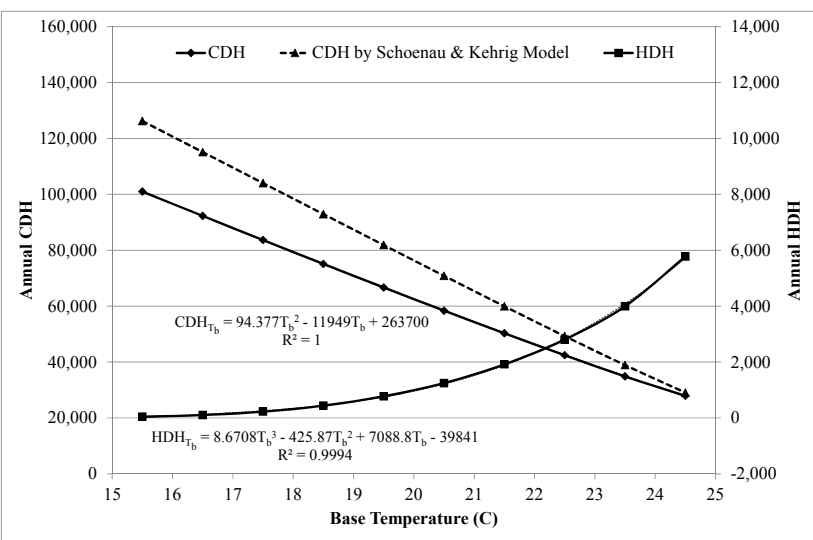

Fig. 12. Annual $\mathrm{CDH}$ and $\mathrm{HDH}$ of Ubonratchathani at various base temperatures.

\section{CONCLUSIONS}

The method to calculate CDH and HDH is trivial but the procedure that is used to create annual hourly dataset that can represent typical temperature data is matter. In this paper, the Sandia method is implemented. Thailand is located close to the equator where the weather is hot and humid. The outside temperature is quite high, for which space cooling is required throughout the year, especially in April and May. There are only a few months when the outside temperature is low in the northern and the north-eastern region. However, space heating of a building is not commonly required.

Monthly and annual CDH is very high in all regions compared to HDH. It is obvious that space cooling plays an important role in energy consumption of air-conditioned buildings to comfort users of the buildings. In commercial and residential buildings, energy consumed in cooling systems is approximately $60-70 \%$ of the total energy consumption of the buildings. A measure that can improve cooling system performance will have a great effect on energy consumption of the buildings.

Annual $\mathrm{CDH}$ and $\mathrm{HDH}$ at various base temperatures are also presented along with regression models for each station. They are inversely proportional to each other and able to model with simple $2^{\text {nd }}$ and $3^{\text {rd }}$ order polynomial equations. The selected stations are located in the capital of each region in which the outside temperature is not much different. The developed models may be used to predict annual $\mathrm{CDH}$ and $\mathrm{HDH}$ in the other areas within the region in case of the absence of the temperature data in such areas.

\section{ACKNOWLEDGMENT}

I would like to thank Ms. Nittaya Phiakaew and Thai Meteorological Department for providing sets of historical temperature data of Thailand.

\section{REFERENCES}

[1] D. Thevenard, "Methods for estimating heating and cooling degree-days to any base temperature," ASHRAE Transactions, vol. 117, pp. 1, pp. 884-891, 2011

[2] F. Jiang, X. Li, B. Wei, R. Hu, and Z. Li, "Observed trends of heating and cooling degree-days in Xinjiang province, China," Theoretical \& Applied Climatology, vol. 97, pp. 349-360, 2009.

[3] M. Kolokotroni, Y. Zhang, and R. Giridharan, "Heating and cooling degree day prediction within the London urban heat island area," Building Services Engineering Research and Technology, vol. 30, no. 3, pp. 183-202, 2009.

[4] M. Kadioglu, Z. Sen, and L. Gultekin, "Variations and trends in Turkish seasonal heating and cooling degree-days," Climate Change, vol. 9, pp. 209-223, 2001.

[5] O. J. Adigun and J. A. Olorunmaiye, "Modeling of cooling degree-days for Southern Nigeria using beta distribution," Journal of Engineering and Technology, vol. 3, no. 2, pp. 1-7, 2005.

[6] Z. Oktay, C. Coskun, and I. Dincer, "A new approach for predicting cooling degree-hours and energy requirements in buildings," Energy, vol. 36, pp. 4855-4863, 2011.

[7] G. Krese, M. Prek, and V. Butala, "Incorporation of latent loads into the cooling degree days concept," Energy and Buildings, vol. 43, pp. 1757-1764, 2011.

[8] G. Krese, M. Prek, and V. Butala, "Analysis of building electric energy consumption data using and improved cooling degree day method," Journal of Mechanical Engineering, vol. 58, no. 2, pp. 107-114, 2012.

[9] S. Wilcox and W. Marion, "User's manual for TMY3 data sets," Technical Report, NREL/TP-581-43156, April 208.

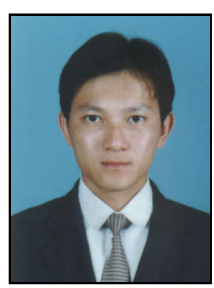

Kriengkrai Assawamartbunlue was born in Bangkok, Thailand. He earned a bachelor degree in mechanical engineering from Chiangmai University, Thailand in 1993. In 1996, he finished a master degree in mechanical engineering from the George Washington University, Washington D.C., USA. In 2000, he completed a doctoral degree in building system engineering, University of Colorado at Boulder, USA.

He currently works as an assistant professor at Mechanical Engineering Department, Kasetsart University, Thailand. He is the head of Energy Technology Research Group that researches and develops projects in the fields of energy conservation and renewable energy. He also interests in building controls and artificial intelligent systems. 